\title{
Maintenance Implementation Plan for Fuel Supply Shutdown
}

Date Published

June 1995

Prepared for the U.S. Department of Energy Office of Environmental Restoration and Waste Management

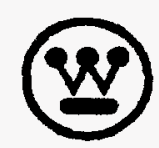

Hanford Company Richland, Washington

Hanford Operations and Engineering Contractor for the

U.S. Department of Energy under Contract DE-AC06-87RL10930

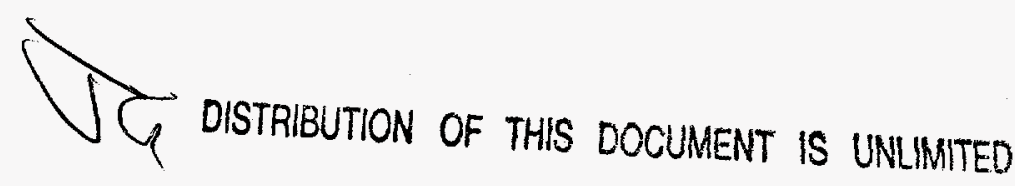

Approved for Public Release 


\section{DISCLAIMER}

This report was prepared as an account of work sponsored by an agency of the United States Government. Neither the United States Government nor any agency thereof, nor any of their employees, make any warranty, express or implied, or assumes any legal liability or responsibility for the accuracy, completeness, or usefulness of any information, apparatus, product, or process disclosed, or represents that its use would not infringe privately owned rights. Reference herein to any specific commercial product, process, or service by trade name, trademark, manufacturer, or otherwise does not necessarily constitute or imply its endorsement, recommendation, or favoring by the United States Government or any agency thereof. The views and opinions of authors expressed herein do not necessarily state or reflect those of the United States Government or any agency thereof. 


\section{DISCLAIMER}

Portions of this document may be illegible in electronic image products. Images are produced from the best available original document. 


\section{RELEASE AUTHORIZATION}

\section{Document Number: WHC-SP-1155}

Document Title: MAINTENANCE IMPLEMENTATION PLAN FOR FUEL SUPPLY SHUTDOWN

Release Date: $\quad 5 / 30 / 95$

This document was reviewed following the procedures described in WHC-CM-3-4 and is:

APPROVED FOR PUBLIC RELEASE

WHC Information Release Administration Specialist:

Chria Stillinghano

C. Willingham

$5 / 30 / 95$ 
• 
MAINTENANCE IMPLEMENTATION PLAN

FOR

FUEL SUPPLY SHUTDOWN

Prepared by:

RL Sentrusen

RL Stephenson

Approved by: $\frac{3 / 30 / 95}{\text { Date }}$

$\frac{3 / 30 / 95}{\text { Date }}$ 
WHC-SP-1155

Revision 0

This page intentionally left blank. 


\section{WHC-SP-1155 \\ Revision 0}

\section{FOREWORD}

This Maintenance Implementation $P l a n$ is written to satisfy the requirements of DOE Order 4330.4B, "MAINTENANCE MANAGEMENT PROGRAM", that specifies the general policy and objectives for the establishment of DOE controlled maintenance programs. These programs provide for the management and performance of cost-effective maintenance and repair of Department of Energy (DOE) property, which includes facilities.

A review of DOE Order 4330.4B, particularly Chapter II the nuclear portion, against existing WHC site programs and policies has provided assurance that most requirements of this order have already been implemented by existing WHC programs. Applicable requirements and guidelines of 4330.4B that are deficient or not implemented are presently being developed and implemented through WHC site policies and programs. Where no program is presently identified or being developed for $4330.4 \mathrm{~B}$ requirements, responsibility for implementation has been assigned within this plan. 
WHC-SP-1155

Revision 0

This page intentionally left blank. 
WHC-SP-1155

Revision 0

TABLE OF CONTENTS

SECTION

DESCRIPTION

PAGE

1.0 EXECUTIVE SUMMARY . . . . . . . . . . . . . . 1-1

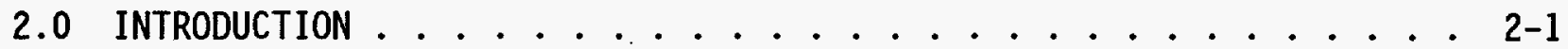

2.1 Facility Complex Description ............. 2-1

2.2 Mission .............. . . 2-1

2.3 History/Scheduled Life .............. 2-2

3.0 DOE ORDER 4330.4B REQUIREMENTS ............... . . . .

3.1 Maintenance Management Program Scope . . . . . . . . . . 3-1

3.2 Maintenance Program Requirements . . . . . . . . . . 3-1

3.3 Graded Approach Strategy . . . . . . . . . . . . . 3-2

3.3.1 Overall Strategy and Basis . . . . . . . . . 3-3

3.3.2 Strategy for Safety Related Items . . . . . . . 3-3

4.0 DOE ORDER 4330.4B CHAPTER II REQUIREMENTS ............ 4-1

4.1 Evaluation of Compliance Elements . . . . . . . . . . . . 4-1

4.2 Maintenance Organization and Administration . . . . . . . 4-1

4.2.1 Maintenance Organization Policies ......... 4-1

4.2.2 Maintenance Strategy .............. 4-1

4.2.3 Staffing Resources............... 4-1

4.2.4 Goals and Objectives .............. 4-2

4.2.5 Accountability ............. 4-2

4.3 Training and Qualification .......... 4-2

4.4 Maintenance Facilities, Equipment, and Tools . . . . . . 4-2

4.5 Types of Maintenance . . . . . . . . . . 4-2

4.5.1 Master Equipment List . . . . . . . . . 4 4-2

4.5.2 Types of Maintenance . . . . . . . . . . 4-3

4.5.3 Maintenance Action and Frequency Selection ...... 4-3

4.5.4 Scheduling ............... 4-3

4.6 Maintenance Procedures ... . . . . . . . . . . 4-3

4.6.1 Procedure Development and Writing ......... 4-4

4.6.2 Procedure Verification ............ 4-4

4.6.3 Procedure Validation ............. 4.4 4.4

4.6.4 Procedure Approval . . . . . . . . . . . . . 4-5

4.6.5 Procedure Use ............ . . . 4-5

4.7 Planning, Scheduling, and Coordination of Maintenance . . 4-5

4.7.1 Planning for Maintenance Activities . . . . . . . 4-5

4.7.2 Scheduling Maintenance Activities ... . . . . . 4-6

4.7.3 Coordination of Maintenance Activities . . . . . . . 4-6

4.7.4 Outage Planning, Scheduling, and Coordination ... 4-6

4.8 Control of Maintenance Activities . . . . . . . . . . . 4-7

4.8.1. Work Control Procedure . . . . . . . . . . . . 4-7

4.8.2 Work Request . . . . . . . . . . . . . 4-7

4.8.3 Supervision of Maintenance Activities . . . . . . . 4-7

4.8.4 Review of Completed Work Requests . . . . . . . . . 4-8

4.8.5 Temporary Repairs .............. . 4-8

4.8.6 Control of Nonfacility Contractor and Subcontractor

4.9 Post-Maintenance Testing $\ldots \ldots$. . . . . . . 
WHC-SP-1155

Revision 0

4.9.1 Post-Maintenance Test Requirements . . . . . . . 4-9

4.9.2 Post-Maintenance Test Program Scope . . . . . . . . 4-9

4.9.3 Post-Maintenance Test Control .......... 4-9

4.9.4 Post-Maintenance Test Performance Documentation and

Acceptance . . . . . . . . . . . 4-9

4.10 Procurement of Parts, Materials, and Services . . . . . . . 4-10

4.10.1 Procurement Policy and Procedures ........ . . 4-10

4.10.2 Procurement Initiation ............ 4-10

4.10.3 Procurement Contro1 . . . . . . . . . . . 4-11

4.10 .4 Services. . . . . . . . . . . . . 4-11

4.11 Material Receipt, Inspection, Handling, Storage, Retrieval, and Issuance .................. . . . . . . .

4.12 Control and Calibration of Measuring and Test Equipment . . . . 4-11

4.13 Maintenance Tools and Equipment Control . . . . . . . . . 4-12

4.14 Facility Condition Inspection ............ 4-12

4.14.1 Standards . . . . . . . . . . . . . 4-12

4.14 .2 Training . . . . . . . . . . . . 4-12

4.14.3 Procedures . . . . . . . . . . . . . . 4-12

4.14.4 Scope of Inspections . . . . . . . . . . . . 4-13

4.14.5 Inspection Program Elements ........... 4-13

4.14.6 Reporting Deficiencies............ . 4-13

4.14.7 Deficiency Follow-up . . . . . . . . . . . . . 4-14

4.15 Management Involvement ... . . . . . . . . . . 4-14

4.15.1 Management Involvement . . . . . . . . . 4-14

4.15.2 Performance Indicators, Goals, and Objective Results . . 4-15

4.15.3 Feedback ................. 4-15

4.15.4 Program Reviews .............. . . 4-15

4.16 Maintenance History . . . . . . . . . . . . . . . . . 4-16

4.17 Analysis of Maintenance Problems . . . . . . . . . . . . 4-16

4.18 Modification Work . . . . . . . . . . . . . . 4-16

4.18.1 Maintenance Program Interface with Modifications . . . 4-16

4.18.2 Temporary Repairs or Temporary Modifications . . . . . . 4-17

4.19 Additional Maintenance Management Requirements ... . . . . 4-17

4.19.1 Seasonal Facility Preservation Requirements . . . . . . 4-17

5.0 DEVIATIONS REQUESTED WITH SUPPORTING RATIONALE . . . . . . . 5-1

6.0 IMPLEMENTATION SCHEDULE . . . . . . . . . . . . 6-1

7.0 BIBLIOGRAPHY . . . . . . . . . . . . . 7-1 
WHC-SP- 1155

Revision 0

\section{LIST OF TERMS}

$\begin{array}{ll}\text { ALARA } & \text { As Low As Reasonably Achievable } \\ \text { AMS } & \text { Action Management System (Division-wide) } \\ \text { CERCLA } & \text { Comprehensive Environmental Response, Compensation, and Liability } \\ & \text { Act } \\ \text { D\&D } & \text { Decontamination and Decommission } \\ \text { DOE } & \text { Department of Energy } \\ \text { EASF } & \text { Environmental Archive Storage Facility } \\ \text { EDRTS } & \text { Environmental Data Remedial Tracking System } \\ \text { EPA } & \text { Environmental Protection Agency } \\ \text { FSS } & \text { Fuel Supply Shutdown } \\ \text { HATS } & \text { Hanford Action Tracking System (Company-wide) } \\ \text { ICF-KH } & \text { ICF-Kaiser Hanford South Programmatic Services } \\ \text { JCS } & \text { Job Control System } \\ \text { LAN } & \text { Local Area Network } \\ \text { M\&TE } & \text { Measuring and Test Equipment } \\ \text { MEL } & \text { Master Equipment List } \\ \text { MIP } & \text { Maintenance Implementation Plan } \\ \text { OJT } & \text { On-the-Job Training } \\ \text { PM/S } & \text { Preventive Maintenance/Surveillance } \\ \text { RCRA } & \text { Resource Conservation and Recovery Act } \\ \text { SAD } & \text { Safety Assessment Document } \\ \text { SEL } & \text { Safety Equipment List } \\ \text { WHC } & \text { Westinghouse Hanford Company }\end{array}$ 
WHC-SP-1155

Revision 0

This page intentionally left blank. 


\subsection{EXECUTIVE SUMMARY}

This Maintenance Implementation $\mathrm{Pl}$ an has been developed for maintenance functions associated with Fuel Supply Shutdown (FSS). This plan is developed from the guidelines presented by Department of Energy (DOE) Order 4330.4B, Maintenance Management Program (DOE 1994), Chapter II.

The objective of this plan is to provide baseline information for establishing and identifying WHC conformance programs and policies applicable to implementation of DOE order 4330.4B guidelines.

FSS is currently undergoing transition activities required for permanent closure and transfer to the decontamination and decommission program. Primary responsibility for the performance and oversight of maintenance activities at FSS resides with Westinghouse Hanford Company (WHC). Maintenance at FSS is performed by ICF-Kaiser Hanford (ICF-KH) South Programmatic Services crafts persons.

This FSS Maintenance Implementation Plan provides interface requirements and responsibilities as they apply specifically to FSS in its shutdown status.

The discussion sections, as applied to implementation at FSS, have been developed from a review of programs and practices utilizing the graded approach. This document is revised as necessary to maintain compliance with DOE requirements. 
WHC-SP-1155

Revision 0

This page intentionally left blank. 
WHC-SP-1155

Revision 0

\subsection{INTRODUCTION}

\subsection{Facility Complex Description}

FSS is located in the northeast corner of the 300 area. The facility includes the following buildings with noncontiguous boundaries: 313 , $333,303-A, 303-B, 303-E, 303-G, 303-K / 3707-G, 303-M, 304,334,334-A$, 3712,3716 , M0-052 (office trailer used by Westinghouse Hanford and contractor personne1), and the Outside Storage and Transfer System including the 311 Tank Farm and the 303-F pump house.

Only 333, 303-A, 303-B, 303-E, 303-G, 3712 and 3716 are identified as nuclear category three buildings. All others are classified as radiological buildings and are not included within this MIP. Currently, the 333 Building does not process, store, or handle nuclear category three quantities of SNM and will not be included under this plan until such time its inclusion (if ever) is warranted.

\subsection{Mission}

The FSS facility originated in 1943 to fabricate fuel for the Hanford single pass reactors. Actual production started in 1944 and lasted until 1960. Various types of fuels were designed, tested, and produced in the FSS facilities during these years. The 313 Building contained the majority of the fuels production equipment during this time. That equipment has since been removed.

Constructed in 1958, the 333 Building was designed to house the primary production equipment for the fabrication of fuel for the NEW(N)-Reactor. The various other FSS buildings were modified to support waste disposal, essential material storage, and other support activities associated with the fabrication of fuel for the $N$ Reactor. Actual fuel fabrication began in 1962 and lasted until 1987 when the N Reactor was placed on standby status. Standby of the $N$ Reactor resulted in a standby status for FSS. Equipment and materials were inventoried, placed in storage, or removed from service.

The facility is currently undergoing transition activities required for permanent closure and transfer to the Decontamination and Decommission Program.

\subsection{History/Scheduled Life}

The history of the facility began in 1943 when the 313 Building was constructed to house manufacturing equipment for production of fuel for the Hanford single pass reactors. Fuel production began in mid 1944 and continued through the early 1950s. The facility was then expanded to allow for increased fuel production. In the late 1960s, the process, which included nickel plating of the bare uranium cores prior to cladding, was developed and installed. This process continued until 1971, when the six production lines were shut down concurrent with the shutdown of the single pass reactors. Other programs conducted near the 313 Building include support of a tritium production program from 1948 to 1952 and a thorium program in the mid 1960s. For $N$ Reactor fuel fabrication, the 313 Building housed a waste treatment system, 
administrative offices, and training and warehouse space. This building also housed a complete $N$ Reactor pressure tube fabrication facility consisting of a 4000 ton Sutton extrusion press, draw bench, grinders, autoclaves, inspection equipment, and chemical cleaning equipment. The Hanford Metal Working process equipment has been sold to a commercial company, and the north section of the 313 Building has been leased for three years for the commercial operation of the extrusion equipment.

The 333 Building, constructed in 1958, houses the primary fabrication equipment for manufacturing $N$ Reactor fuel, which began in 1962 . From 1965 to 1967, the building was also used to assemble 1 ithium aluminate targets for demonstration of coproduction in the $N$ Reactor. The building contained equipment for all operations from initial component cleaning to finished fuel assembly, inspection, and packaging for shipment.

Fabrication activities continued until $N$ Reactor entered the standby phase in 1987, and at that time, the facility also began transition to standby status. The 333 Building may be used in the future to support the packaging of SNM for relocation to another site for beneficial use, continued long term storage, or dispositioned as waste. Other buildings comprising the facility provide storage space for fuel materials and finished fuel, and contain residual process equipment that supported fuel production.

At this time, the Fuel Supply Shutdown complex is in transition from standby status and undergoing cleanup and shutdown activities required for permanent closure and transfer to decontamination and decommissioning (D\&D). 
WHC-SP-1155

Revision 0

\subsection{DOE ORDER 4330.4B REQUIREMENTS}

\subsection{Maintenance Management Program Scope}

The Maintenance Management Program for FSS encompasses buildings 303-A, 303-B, 303-E, 303-G, 3712 and 3716 which are associated with the FSS Facility. Maintenance activities associated with the FSS Facility are provided by the FSS Work Control and ICF-KH. These activities, whether for building upkeep or for repair, calibration and/or rework of equipment, are performed by the ICF-KH maintenance organization. The total budget for this program scope is $\$ 50,000$ or less.

\subsection{Maintenance Program Requirements}

System and component maintenance requirements are established based on analyses that consider safety classifications, programmatic concerns; risk assessments of the facility, system, and component; requirements derived from WHC-SD-NR-ISB-001, Interim Safety Basis for Fuel Supply Shutdown Facility, and operating experiences and maintenance history. They address the following DOE Order 4330.4B requirements:

Requirement: (1) The structures, systems, and components included, using a graded approach and the requirements derived from Technical Safety Requirements.

Discussion:

WHC-SD-NR-ISB-001 defines operational safety requirements.

Requirement: (2) The management systems used to control maintenance activities, including the means for monitoring and measuring the effectiveness of the program and the management of maintenance backlog.

Discussion:

FSS maintenance activities are managed and controlled in accordance with WHC-CM-1-8, Work Management

Manual. WHC-CM-1-8 includes means for monitoring and measuring program effectiveness and backlog management through the Job Control System (JCS).

Requirement: (3) The assignment of responsibilities and authority for all levels of the maintenance organization.

Discussion:

The FSS Work Control supervisor is responsible for maintaining a trained, qualified staff to support the administration of maintenance needs for the FSS Facility. ICF-KH is matrixed to WHC to provide maintenance craft support; hence, the ICF-KH Maintenance Supervisor is responsible for directing field work activities.

Requirement: (4) Mechanisms for feedback of relevant information, such as trend analysis and instrumentation performance and reliability data, to identify necessary program modifications. 
WHC-SP-1155

Revision 0

Discussion: $\quad$ Addressed in WHC-CM-1-8.

Requirement: (5) Provisions for identification, evaluation, and correction of possible component, system design, quality assurance, or other relevant problems.

Discussion: $\quad$ Addressed in WHC-CM-1-8.

Requirement: (6) Performance indicators and criteria to be utilized to measure equipment, systems, and personnel effectiveness in maintenance activities.

Discussion: $\quad$ Addressed in WHC-CM-1-8.

Requirement: (7) Interfaces between maintenance and other organizations (i.e., operations, engineering, quality, training, environment, safety, and health).

Discussion: $\quad$ Defined in WHC-CM-5-35

Requirement: (8) A self assessment program to monitor the effectiveness and efficiency of the maintenance program.

Discussion: Assessments of the maintenance activities at the FSS Facility are performed when deemed appropriate, when major changes to maintenance policy and practice so warrants, or as required by the Order (every two years).

Requirement: (9) Provisions for planning, scheduling, and coordination of maintenance activities.

Discussion: $\quad$ Addressed by WHC-CM-1-8 and the JCS.

\subsection{Graded Approach Strategy}

"Graded Approach" is defined as the depth of detail required for implementation and the magnitude of resources expended for a particular maintenance management element.

\subsubsection{Overall Strategy and Basis}

A graded approach is used to identify the depth of detail and the level of commitment required to ensure safe and reliable operations, environmental compliance, programmatic mission, and facility preservation. Personnel and public safety, availability of funding, operational safety/reliability, environmental safety/compliance, safeguards and security, programmatic mission, and other facility 
WHC-SP-1155

Revision 0

specific requirements are to be considered when work is prioritized and performed.

\subsubsection{Strategy for Safety Related Items}

System and equipment safety classification and risk categories are assigned in accordance with established Westinghouse Hanford procedures and criteria. These categories support a graded approach to maintenance activities including assignment of level of review and approval, work control, procedural detail and requirements, documentation, historical records, oversight, and methods of verification and validation. The philosophy for work priority and allocation of resources dictates that correction of discrepancies having a direct impact on safety receives higher priority than non-safety related items or plant enhancements.

WHC-CM-3-5, Document Control and Records Management Manual, provides control of appropriate application of maintenance activities. 
WHC-SP-1155

Revision 0

This page intentionally left blank. 


\subsection{DOE ORDER 4330.4B CHAPTER II REQUIREMENTS}

\subsection{Evaluation of Compliance Elements}

The Hanford Site has existing programs and administrative guidelines providing for control and implementation of a maintenance program conforming to DOE Order 4330.4B. FSS does not have a maintenance organization within the facility. Maintenance activities within the facility are coordinated by the facility work control center; however, all other maintenance functions are provided by ICF-KH.

\subsection{Maintenance Organization and Administration}

The organization and administration of the maintenance function ensures a high level of performance is achieved through effective implementation and control of maintenance activities.

\subsection{1}

Maintenance Organization Policies

Objective: To establish and communicate policies, procedures, and standards for the administration, implementation and control of maintenance activities.

Discussion: FSS does not have a maintenance organization. Maintenance activities within the facility are provided by ICF-KH which establishes its own policies, procedures, and standards for administration, implementation, and control of maintenance activities.

Improvement: No improvement is needed at this time.

\subsection{2}

\section{Maintenance Strategy}

Objective: To establish an integrated approach (including al1 affected organizations) in performance of maintenance activities which uses strategic planning to establish specific goals for the maintenance program.

Discussion: Only basic maintenance is required in the nuclear storage areas since no processes are involved. Buildings involved require only periodic surveillance and building structural maintenance.

Improvement: No improvement is needed at this time.

\section{2 .3}

\section{Staffing Resources}

Objective: To assemble and maintain a maintenance organization staff selected to prescribed qualification criteria commensurate with the facility mission(s), and maintaining the level of skill for maintenance personnel through training and incentive programs.

Discussion: FSS does not have any maintenance organization resources. A11 resources are provided by ICF-KH. 
WHC-SP-1155

Revision 0

Improvement: No improvement is needed at this time.

\subsubsection{Goals and Objectives}

Objective: Establish maintenance goals to monitor maintenance activity progress, detect development of trends (favorable and unfavorable), improve performance, create a safe working environment, and measure overall maintenance program effectiveness.

Discussion: The FSS maintenance goals are simply to maintain the storage areas in a stable condition until all fuel is transferred out and transition to D \& D is complete.

Improvement: No improvement is needed at this time.

\section{2 .5}

Accountability

Objective: To monitor personnel in the performance of their assigned responsibilities and administer recognition or disciplinary actions as appropriate to individual performance.

Discussion: Existing ICF-KH procedures provide for performance reviews and critiques of maintenance personnel.

Improvement: No improvement is needed at this time.

\subsection{Training and Qualification}

A maintenance training and qualification program consistent with $D O E$ Orders 5480.5, 5480.6, 5480.20, and 5480.18A is established and controlled by WHC-CM-2-15, Training Administration Manual.

The responsibility for maintaining a staff of qualified and well-trained maintenance personnel lies with ICF-KH.

\subsection{Maintenance Facilities, Equipment, and Tools}

Maintenance facilities, equipment, and tools efficiently support facility maintenance and maintenance training.

There are no maintenance facilities, equipment, or tools maintained within FSS. All such facilities, equipment and tools are provided by ICF-KH.

\subsection{Types of Maintenance}

A proper balance of corrective and preventive maintenance should be employed to provide a high degree of confidence facility equipment degradation is identified and corrected, that equipment life is optimized, and the maintenance program is cost effective.
4.5.1
Master Equipment List 
WHC-SP-1155

Revision 0

Objective: Develop (and maintain) a MEL for use in identifying equipment safety classifications and maintenance program scope, and development of the equipment history file.

Discussion: FSS does not have a MEL; however, the onty equipment within the nuclear storage buildings is that associated with the fire protection system. Due to the status of the facility, no MEL will be developed.

Improvement: No improvement is needed at this time.

\section{5 .2}

Objective:

Discussion:
Improvement: No improvement is needed at this time.

\section{Types of Maintenance}

Develop a maintenance program that establishes an appropriate and cost effective balance of preventive, predictive, and corrective maintenance to minimize equipment downtime and provide a high degree of confidence that facility equipment degradation is identified and corrected.

Only basic corrective maintenance is required in the nuclear storage areas since no processes are involved. The only preventive or predictive maintenance being performed is that done on the fire protection system.

\section{5 .3}

objective:

\section{Maintenance Action and Frequency Selection}

Maintenance frequencies are established to satisfy code and specification requirements, and to ensure optimum equipment operating life and performance.

Discussion: A11 fire system maintenance actions and preventive maintenance frequency selections are made by the site-wide fire systems testing/maintenance organization.

Improvement: No improvement is needed at this time.

\section{5 .4}

Objective:

\section{Scheduling}

\section{Preventive maintenance activities are scheduled according} to assigned frequencies and in conjunction with corrective maintenance of the same equipment or with other activities related to equipment.

Discussion: The only preventive maintenance activities in the nuclear storage buildings are on the fire protection system. All scheduling of corrective and preventive maintenance on the fire systems is done by the site-wide fire systems testing/maintenance organization.

Improvement: No improvement is needed at this time.

\subsection{Maintenance Procedures}


Maintenance procedures and other work-related documents (e.g., drawings and instructions) are prepared and used to provide appropriate work direction and to ensure that maintenance is performed safely and efficiently. A balance of written guidance, craftsman's skills, and work-site supervision (graded approach) is required to achieve the quality workmanship essential to safe and reliable facility operation.

4.6.1

Objective: Procedures are provided for performance of maintenance activities to any facility or equipment component designated as safety-related, has complex maintenance tasks, is beyond the skills possessed by the craftsman, or that presents a personnel or equipment hazard.

Discussion: Corrective maintenance procedures are prepared by facility engineers and ICF-KH engineers. Preventive maintenance procedures are prepared by other procedure development resources. The content and detail included in the procedures are determined by site-wide work control procedures based on the safety-related designation of the equipment, complexity of the task, and personnel hazards involved.

Improvement: No improvement is needed at this time.

\section{Procedure Verification}

Objective: Procedures are reviewed for format and technical accuracy. Format used incorporates human factors principles and other administrative policies. Reviews are conducted by other than the procedure writer.

Discussion: All corrective and preventive maintenance procedures are reviewed and approved in accordance with the requirements of WHC-CM-3-5. The impact of the work on the facility, complexity of the job, and hazards involved are all considered when determining review and approval requirements.

Improvement: No improvement is needed at this time.

\section{Procedure Validation}

Objective: Procedures are reviewed for usability and correctness to ensure sufficient and understandable instructions are provided and are compatible to the equipment and task specified.

Discussion: The only preventive maintenance procedures used in the nuclear storage buildings are fire systems preventive maintenance procedures which have all been validated.

Improvement: No improvement is needed at this time. 


\section{6 .4}

Objective:

Improvement: No improvement is needed at this time.

\section{Procedure Approval} levels of management.

Discussion: All corrective and preventive maintenance procedures are

Procedures are reviewed to applicable specifications and administrative procedures and approved by appropriate approved in accordance with the requirements of WHC-CM-3-5.

4.6.5

Procedure Use

Objective: Procedure control is established ensuring availability and currency of the procedures to be used. Procedure compliance requirements are clearly stated, communicated, and understood by users.

Discussion: Maintenance of preventive maintenance procedures for the FSS nuclear storage buildings is the responsibility of the fire systems testing/maintenance organization. The procedure compliance policies of the facility, as well as the company, are well understood by personnel.

Improvement: No improvement is needed at this time.

\subsection{Planning, Scheduling, and Coordination of Maintenance}

An effective system for $\mathrm{planning,} \mathrm{scheduling,} \mathrm{and} \mathrm{coordinating}$ maintenance activities are implemented in order to ensure that maintenance is accomplished in a timely manner, improve maintenance efficiency, reduce radiation exposure, and increase equipment availability.

\section{7 .1}

Planning for Maintenance Activities

Objective:

Establish a planning program that provides work instructions, identifies resource requirements, and coordinates support functions.

Discussion: Planning Group Organization

All planning activities for FSS are performed by ICF-KH and the FSS Work Control group utilizing the JCS in accordance with WHC-CM-1-8. 
WHC-SP-1155

Revision 0

Discussion: Planning Group Responsibilities

The FSS Work Control is responsible for coordinating maintenance activities at FSS Facilities in accordance with existing site procedures.

Improvement: No improvement is needed at this time.

4.7 .2

objective:

Discussion:

Discussion: Work Priority

The FSS Work Control assigns work priorities on the basis of safety and operational requirements, using the graded approach. Assignment of work priorities is controlled by requirements of WHC-CM-1-8.

The weekly planning meeting, plan-of-the-week, and plan-ofthe-day are used for integrating work priorities with the long range schedule.

Improvement: No improvement is needed at this time.

\section{7 .3}

objective:

Discussion: of activities. The FSS Work Control provides the necessary direction to assure all maintenance activities are performed in cooperation and coordination with other organizations.

Improvement: No improvement is needed at this time.

4.7.4

Objective: Establish program for identifying all maintenance activities to be performed during a defined facility or equipment outage and develop schedule for planning and performance of those activities. 
Discussion: Outage planning is not applicable to FSS as there are no regularly scheduled outages at the facility.

Improvement: No improvement is needed at this time.

\subsection{Control of Maintenance Activities}

Management directed and delegated involvement in control of maintenance activities ensure maintenance practices are effective in maintaining safe, efficient, and reliable facility operation.

4.8.1

Objective:

Discussion:

Improvement: No improvement is needed at this time.

\section{8 .2}

Objective:

Discussion:

\section{Work Request}

All maintenance activities performed are controlled by the facility work control program. Work request documents clearly define work to be performed, equipment on which work is to be performed, pre (and post) requisites, and documentation requirements. Work requests are reviewed by affected organizations before release for work and upon completion of work.

Facility specific work control procedures are very specific on the requirements for processing a work package. A graded approach, based on personnel safety and impact on the facility, has been developed to define the amount of control placed on various types of work. Approvals and reviews of work documents are based on the site-wide Approval Designator System.

Improvement: No improvement is needed at this time.

\subsection{3}

\section{Supervision of Maintenance Activities}

Objective:

Maintenance managers routinely monitor work in progress to ensure maintenance activities are conducted in accordance with facility procedures and work package instructions. Problems observed are analyzed and feedback is provided to prevent recurrence. 
WHC-SP-1155

Revision 0

Discussion: The FSS Work Control and the ICF-KH Maintenance Supervisor routinely monitor work in progress to help ensure maintenance activities are conducted in accordance with DOE and site policies and procedures.

Improvement: No improvement is needed at this time.

4.8 .4

Objective:

\section{Review of Completed Work Requests}

Completed work packages are reviewed to verify all work items, including post-maintenance testing and inspections, have been completed in an acceptable manner before returning system or equipment to service.

Discussion: The site-wide JCS, as well as the facility specific work control procedure, calls for a review of the work, clean up of the work site, and performance of necessary postmaintenance testing, all before a work package is signed off as complete.

Improvement: No improvement is needed at this time.

\section{Temporary Repairs}

Objective: Temporary repairs are accomplished and controlled to the same level as permanent repairs.

Discussion: The installation of temporary modifications are controlled through the JCS to the same degree as permanent modifications or other repair work. Once they are installed, they are monitored until they are removed and the system returned to normal, or until they are reprocessed and documented as a permanent modification.

Improvement: No improvement is needed at this time.

\subsection{6}

Objective: Nonfacility contract and subcontract personnel who perform maintenance or modification work on FSS systems are qualified for the work performed and trained in accordance with access requirements.

Discussion: Site procedures provide for access control and general employee training of contractor and subcontractor personnel. The FSS Work Control assures any additional training required for contractor or subcontractor personnel is performed and documented in accordance with site procedure. Qualification of contractor personnel is certified by the contractor; and verified and documented by the cog engineer before commencement of work activities.

Improvement: No improvement is needed at this time. 
WHC-SP-1155

Revision 0

\subsection{Post-Maintenance Testing}

Post-maintenance testing is performed to verify components can fulfill their design function when returned to service after maintenance.

\section{9 .1}

\section{Post-Maintenance Test Requirements}

Objective: The work completion and retest process at WHC addresses control and documentation of retest requirements. Work requests provide specific instructions for test and acceptance criteria when maintenance work is performed.

Discussion: Post-maintenance testing is an integral part of JCS. Appropriate testing requirements are provided in work packages to ensure that equipment repairs are satisfactory and that the equipment performs its designed function. Operations personnel also have the option of performing additional testing to verify proper operation of the system being worked on.

Improvement: No improvement is needed at this time.

\section{9 .2}

\section{Post-Maintenance Test Program Scope}

Objective: A11 maintenance activities are reviewed for applicability of post-maintenance testing and appropriate testing instructions (and acceptance criteria) are provided.

Discussion: Post-maintenance testing is an integral part of each work package and is reviewed and approved along with the rest of the work package in accordance with the requirements of the JCS and the site-wide Approval Designator System.

Improvement: No improvement is needed at this time.

\section{9 .3}

\section{Post-Maintenance Test Control}

Objective: The work control program addresses control of postmaintenance testing that covers all conditions of single or multiple organization involvement and testing that is deferred until a later date.

Discussion: Post-maintenance testing is an integral part of JCS. The testing is strictly controlled in the same manner as other work steps which precede it. Post-maintenance testing status is tracked in the JCS, and all testing is completed and documented prior to a work package being closed out.

Improvement: No improvement is needed at this time.

\section{9 .4}

Post-Maintenance Test Performance Documentation and Acceptance 
Objective: Post-maintenance testing is performed in accordance with approved work package instructions (or preventive maintenance procedure) and completion is documented.

Discussion: Post-maintenance testing is an integral part of JCS. In addition to any post-maintenance testing performed as part of the work instructions, provisions are made for Operations personnel to specify additional testing to be performed. Operation's acceptance of the testing is a prerequisite to work package close-out. Post review of work packages, including post-maintenance testing, by appropriate organizations is also an integral part of JCS.

Improvement: No improvement is needed at this time.

\subsection{Procurement of Parts, Materials, and Services}

Controls and assessment of procurement activities are used to help ensure that proper parts, materials, and services are purchased to support maintenance activities and to meet the requirements for safe and reliable facility operation.

\subsection{0 .1}

Objective:

Discussion:

\section{Procurement Policy and Procedures}

Policies and procedures are in place governing the procurement of parts, materials, equipment, and services. Personnel responsible for procurement activities are conversant to, and comply with, defined requirements.

Mechanisms are in place to provide for expeditious procurement of parts and material on a high priority basis when needed, as specified in WHC-CM-6-1 and WHC-CM-2-1. WHC-CM-2-2 prescribes methods to acquire replacement parts not available through the original supplier.

The ICF-KH Procurement Specialist is responsible for procurement of parts and materials associated with FSS maintenance activities. The ICF-KH Maintenance Supervisor is responsible for procuring parts associated with shop activities and equipment.

The fire systems testing/maintenance organization is responsible for maintaining an adequate spare parts inventory for the FSS fire protection and alarm system.

Improvement: No improvement is needed at this time.

\subsection{0 .2}

Objective:

\section{Procurement Initiation}

Procurement activities are conducted in a timely fashion. The procurement program addresses the pre-selection and qualification of procurement sources, spare parts inventory, and cross facility use of inventories. 
Discussion: Procurement activities, such as selection and qualification of procurement resources, maintaining spare part inventories, and cross facility use of inventories, is the responsibility of ICF-KH.

Improvement: No improvement is needed at this time.

\subsubsection{Procurement Control}

Objective: The procurement program provides for documentation and controls applicable to obtaining parts, materials, equipment, and services in accordance with the technical and quality requirements.

Discussion: ICF-KH is responsible for routing incoming shipments of general supplies, spare parts, and direct charge items for receiving inspection.

Improvement: No improvement is needed at this time.

4.10 .4

Services

Objective: A program for selection and procurement of service contracts is in place and a renewal process may be initiated to prevent periods of non-coverage. Service contracts include provisions for emergency or short notice support.

Discussion: Selection and procurement of service contracts is the responsibility of ICF-KH.

Improvement: No improvement is needed at this time.

4.11 Material Receipt, Inspection, Handling, Storage, Retrieva1, and Issuance

All phases of receiving, inspecting, handling, storing, retrieving, and issuing equipment, parts, and materials for maintenance are covered by effectively implemented policies and procedures consistent with the Quality Assurance Requirements of the facility.

A11 phases of receiving, inspecting, handling, storing, retrieving and issuing equipment, parts, and materials for maintenance are adequately performed by ICF-KH.

\subsection{Control and Calibration of Measuring and Test Equipment}

The program for control and calibration of measuring and test equipment (M\&TE) are consistent with the Quality Assurance requirements of DOE $5700.6 \mathrm{C}$ and ensure the accurate performance of facility instrumentation and equipment for testing, calibration, and repairs.

The program for control and calibration of measuring and test equipment is adequately administered by ICF-KH. 
WHC-SP-1155

Revision 0

\subsection{Maintenance Tools and Equipment Control}

Methods are established to provide for storage, issuance, and maintenance of an adequate and readily available supply of tools and equipment, and for development of special tools and equipment as needed in the maintenance program.

FSS does not maintain an inventory of maintenance tools and equipment. All maintenance tools and equipment are supplied by ICF-KH.

\subsection{Facility Condition Inspection}

Management conducts periodic inspections of equipment and facilities to assure excellent facility condition, housekeeping, and safe and reliable operation.

4.14 .1

\section{Standards}

Objective: Management conducts periodic inspections of equipment and facilities to assure excellent facility condition and housekeeping. The condition of a facility is dependent on many factors, including design, fabrication, modification, ongoing maintenance, the facility work control programs, and day-to-day operation. After initial facility construction, ongoing maintenance and the control of modifications are prime contributors to keeping systems and equipment in optimum condition to support safe and reliable operation.

Discussion: A program for the periodic inspection of the FSS facility has been set up; however, it has not been formalized. Due to the status of the facility, there are no plans to formalize the program.

Improvement: No improvement is needed at this time.

\subsection{4 .2}

objective:

Discussion:

Discussion:

\section{Training}

Personnel involved in facility inspections receive instructions to establish knowledge of standards and related facility policies. Methods for determining condition status are provided for consistency of inspections and condition reporting.

There is no formal training program for the personnel conducting the periodic facility housekeeping and safety inspections. Due to the small size of the facility and the small number of personnel, it has been determined that building orientation training is sufficient.

Improvement: No improvement is needed at this time.
4.14 .3
Procedures 
Objective: Procedures are provided defining the facility inspection program, methods of implementation, standards of

condition, and means for correction of deficiencies found. Deficiencies found are evaluated for changes to the facility maintenance program.

Discussion: Due to the small size and the status of the facility, it has been determined that formal housekeeping and safety inspection procedures are not necessary.

Improvement: No improvement is needed at this time.

\subsection{4}

objective:

Discussion:

Improvement:

\subsection{4 .5}

objective:

Discussion:

Improvement: No improvement is needed at this time.

\subsection{4 .6}

objective:

\section{Reporting Deficiencies}

Deficiencies noted during inspection are entered into the work control program for corrective action. Significant and/or safety related deficiencies are assigned the appropriate priority and reported to the responsible facility manager. Housekeeping deficiencies are reported to the occupying organization for attention.

Discussion: Deficiencies found during inspections are entered into a database and are tracked to completion. Those deficiencies requiring maintenance support are also entered into the JCS. 
WHC-SP-1155

Revision 0

Improvement: No improvement is needed at this time.

4.14 .7

Objective:

Discussion:

iciencies found during inspections are entered into a database and are tracked to completion. Maintenance of the database allows for periodic review for recurring, generic, and long term problems.

Improvement: No improvement is needed at this time.

\subsection{Management Involvement}

To ensure the safety of DOE facility operations, DOE and contractor corporate and facility managers are sufficiently involved with facility operations to be technically informed and personally familiar with conditions at the operating facility.

\subsection{1}

objective:

\section{Management Involvement}

Objective:

Management conducts periodic inspections of equipment and facilities to assure excellent facility condition and housekeeping. The condition of a facility is dependent on many factors, including design, fabrication, modifications, ongoing maintenance, the facility work control programs, and day-to-day operation. After initial facility construction, ongoing maintenance and the control of modifications are prime contributors to keeping systems and equipment in optimum condition to support safe and reliable operation.

The involvement of facility managers and supervisors in periodic facility walkdowns and inspections clearly displays management standards to all personnel and can significantly improve the condition of the facility. A program for identification and dispositioning of facility condition deficiencies and housekeeping discrepancies is an important step in maintaining facilities and equipment in a condition of maximum safety, reliability, and availability.

Discussion: Due to the small size of the facility, the facility manager is closely involved in facility activities. Maintenance activities are closely overviewed by the facility work control supervisor.

Improvement: No improvement is needed at this time. 
WHC-SP-1155

Revision 0

4.15 .2

Objective:

Performance Indicators, Goals, and objective Results

Performance indicators are established, maintained, and trended to provide visibility of organizational goals and objectives.- Information is used to observe developing trends and formation of corrective action and recovery plans.

Discussion: Maintenance performance indicators and trend data is maintained by ICF-KH.

Improvement: No improvement is needed at this time.

\subsection{5 .3}

objective:

\section{Feedback}

Feedback systems are in $\mathrm{place}$ to provide means for continuous communications between all groups, worker disciplines, and management levels. Methods are in place to apply lessons learned from experiences of others, and in-house, to ensure long-term success. All levels of management are available to discuss problem areas and suggested improvements.

Discussion: A means for feedback on maintenance activities has been established through daily and weekly status/planning meetings between the facility work control supervisor and the ICF-KH maintenance organization.

Improvement: No improvement is needed at this time.

\subsection{5 .4 \\ Program Reviews}

Objective: Managers periodically review and assess all elements of the maintenance program to identify areas requiring improvement or corrective action. Input of managers and supervisors, and other supporting organizations, is utilized in program review. Areas requiring improvement are assigned for corrective action and follow-up.

Discussion: The facility work control supervisor monitors all maintenance activities in the facility and provides ICF-KH feedback to assist in their program reviews and self-assessments.

Improvement: No improvement is needed at this time. 
WHC-SP-1155

Revision 0

\subsection{Maintenance History}

A maintenance history and trending program is maintained to document data, provide historical information for maintenance planning, and support maintenance and performance trending of facility systems and components.

The only maintenance history data maintained for FSS is that contained in the JCS database. Due to the status of the facility and the minimal amount of maintenance being performed, there is no plan to expand on the history data contained in JCS.

\subsection{Analysis of Maintenance Problems}

Systematic analysis is used to determine and correct root causes of unplanned occurrences related to maintenance.

The facility work control supervisor monitors all maintenance activities in the facility and provides ICF-KH feedback on maintenance problems that occur. He also assists them in analyzing events, determining the cause, and establishing corrective actions; however, the overall responsibility for maintenance problem analysis lies with the ICF-KH maintenance organization.

\subsection{Modification Work}

Facility modification work, including temporary modifications, is accomplished under the same basic administrative controls as those applied to facility maintenance activities so there is no increases in risk to facility equipment, environment, or personnel because of the modifications work.

4.18 .1

\section{Maintenance Program Interface with Modifications}

Objective: Modifications are performed in accordance with requirements and 7 imitations of applicable procedures, codes, standards, and specifications.

Discussion: All modification work, both permanent and temporary, is accomplished utilizing the same administrative procedures and guidelines. Modification work packages are reviewed prior to implementation for changes to drawings, procedures, spare parts, and vendor information. A11 required changes must be implemented prior to modification work package close out. Plant modifications are reviewed to ensure that future preventive maintenance and predictive maintenance programs are modified accordingly.

Improvement: No improvement is needed at this time. 


\subsection{8 .2}

Objective:

mprovement:
Discussion: Temporary modifications receive the same overview as

\section{Temporary Repairs or Temporary Modifications}

Temporary repairs or modifications are reviewed in accordance with the facility modification program prior to implementation. Temporary repairs or modifications are tracked after completion for consideration of permanent corrective action. permanent modifications. Temporary modifications are periodically reviewed and an evaluation is made to determine the continued need for the temporary modification. They continue to be tracked until they are removed or made into a permanent modification.

\subsection{Additional Maintenance Management Requirements}

A program is in $\mathrm{p} 7$ ace to prevent equipment and building damage due to cold weather at any nuclear facility that may be at risk.

\subsection{9 .1 \\ Seasonal Facility Preservation Requirements}

objective: Cold weather protection program in place to ensure continued safe facility operations is defined and implemented using approved procedures. Program includes criteria for preparation (and suspension), periodic surveillances, and program effectiveness evaluations. Lessons learned are evaluated and appropriate program changes made to prevent recurrence.

Discussion: A detailed review of the plant facilities and systems has been performed and those actions that are required to protect the $\mathrm{plant}$ assets from seasonal damage have been determined. Several permanent corrective actions have been taken. Other seasonal preventive actions are formally administered through special procedures, standing instructions, and operator log sheets.

Improvement: No improvement is needed at this time. 
WHC-SP-1155

Revision 0

This page intentionally left blank. 
WHC-SP-1155

Revision 0

\subsection{DEVIATIONS REQUESTED WITH SUPPORTING RATIONALE}

No deviations from the policy requirements identified by DOE Order 4330.4B (DOE 1994) are requested at this time. 
WHC-SP-1155

Revision 0

This page intentionally left blank. 


\subsection{IMPLEMENTATION SCHEDULE}

The majority of the maintenance functions at FSS are the responsibility of ICF-KH. Due to the current status of the facility and the minimal amount of maintenance which is being performed, there are no changes to the maintenance management program identified at this time. 
WHC-SP-1155

Revision 0

This page intentionally left blank. 


\subsection{BIBLIOGRAPHY}

DOE, 1994, Maintenance Management Program, DOE Order 4330.4B

DOE, 1991b, Quality Assurance, DOE Order 5700.6C

DOE, 1991a, Accreditation of performance-Based Training for Category A Reactor and Nuclear Facilities

DOE, 1993, DOE-RL Hanford Site Hoisting and Rigging Manual

DOE, Hanford Site Radiological Control Manual, HSRCM-1

ICF-KH, Procedure Writer's Guide, U0-A-00.04

WHC, 7-GN-107, Cold Weather Protection

WHC, WHC-CM-1-4, Corrective Action Management Manual

WHC, WHC-CM-1-8, Work Management Manual

WHC, WHC-CM-2-1, Procurement Manual and Procedures

WHC, WHC-CM-2-2, Materials Management Manual

WHC, WHC-CM-2-15, Training Administration Manua7

WHC, WHC-CM-3-5, Document Control and Records Management Manual

WHC, WHC-CM-4-2, Quality Assurance Manual

WHC, WHC-CM-4-3, Industrial Safety ManuaT

WHC, WHC-CM-6-1, Standard Engineering Practices

WHC, WHC-CM-8-7, Cold Weather Protection

WHC, WHC-SD-NR-ISB-001, Interim Safety Basis for Fuel Supp7y Shutdown Facility

WHC, WHC-CM-5-35, Fuel Supply Operations Control Manual 
WHC-SP-1155

Revision 0

This page intentionally left blank. 
WHC-SP-1155

Revision 0

DISTRIBUTION

Number of Copies

\section{Onsite}

9

Westinghouse Hanford Company

I. L. Metcalf

L6-26

J. M. Steffen

R. L. Stephenson

President's Office

Central Files

Information Release

Administration (2)

N1-47

L6-26

B3-01

L8-04

L8-07

2

ICF Kaiser Hanford Company

L. S. Angerman (2)

L6-61

Distr-1 
WHC-SP-1155

Revision 0

This page intentionally left blank.

Distr-2 